Volume 1 (2019)

ISSN 2612-6966

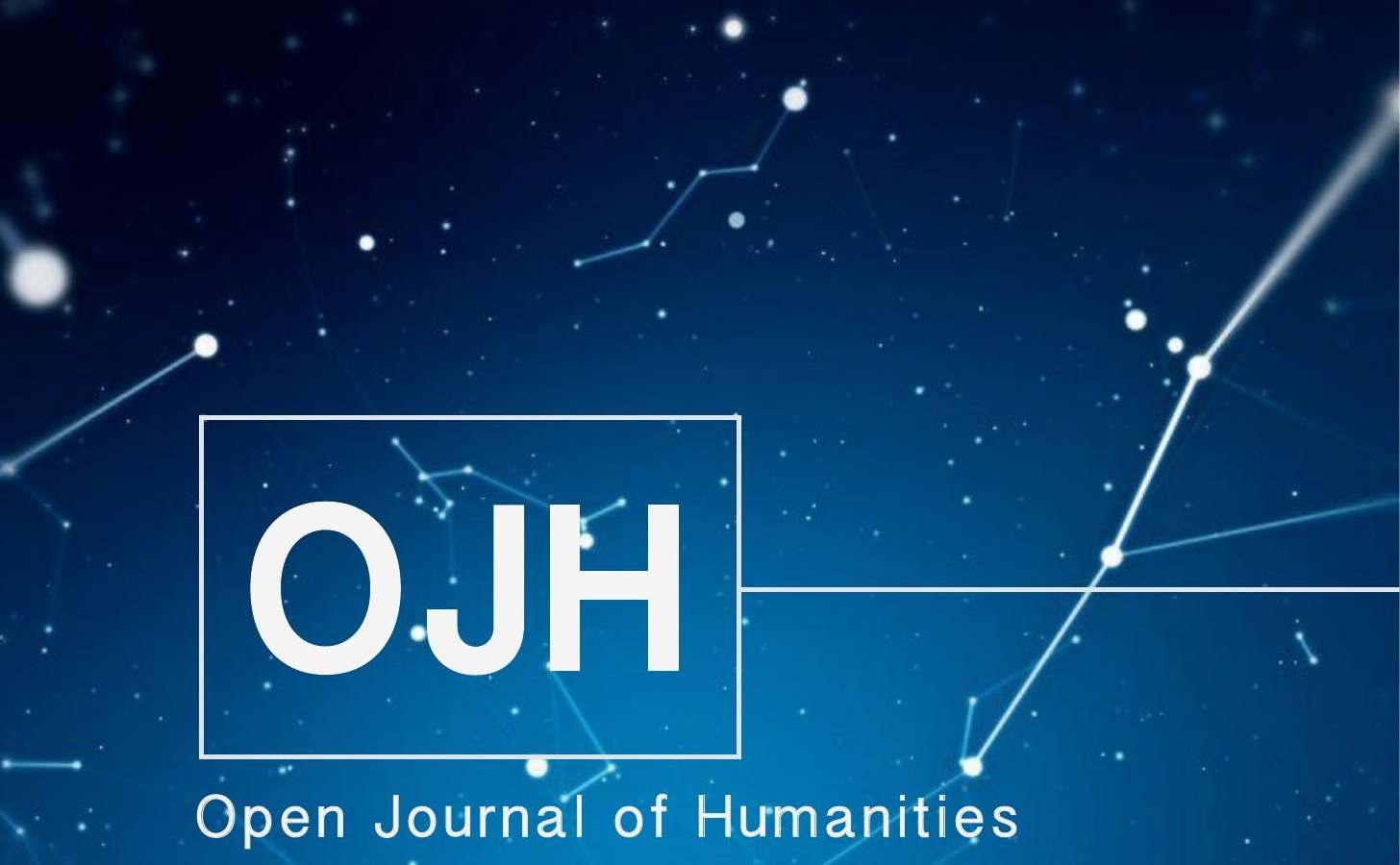




\section{Open Journal of Humanities \\ ISSN 2612-6966}

\section{Publisher}

Universitas Studiorum S.r.I. - Casa Editrice Scientifica

via Sottoriva, 9 - 46100 Mantova (MN), Italy

P. IVA IT02346110204

tel. (+39) 03761810639

www.universitas-studiorum.it

\section{International Scientific Committee}

Carla Carotenuto, Università degli Studi di Macerata (Director)

Gabriella Cambosu, Università degli Studi di Cagliari

Clementica Casula, Università degli Studi di Cagliari

Matteo De Beni, Università degli Studi di Verona

Federica De Iuliis, Università degli Studi di Parma

Francesca Dell'Oro, Université de Lausanne (Switzerland)

Sonia Gambino, Università degli Studi di Messina

Carmela Giordano, Università degli Studi di Napoli "L'Orientale"

Alberto Jori, Università degli Studi di Ferrara

Valetina Laviola, Università degli Studi di Napoli "L'Orientale"

Giovanni Lupinu, Università degli Studi di Sassari

Chiara Melloni, Università degli Studi di Verona

Michela Meschini, Università degli Studi di Macerata

Mario Negri, Università IULM

Erika Notti, Università IULM

Isotta Piazza, Università degli Studi di Parma

Paola Pontani, Università Cattolica del Sacro Cuore

Daniela Privitera, Middlebury College at Mills, San Francisco (USA)

Riccardo Roni, Università degli Studi di Urbino "Carlo Bo"

Marco Sabbatini, Università degli Studi di Pisa

Sonia Saporiti, Università degli Studi del Molise

Domenico Scalzo, Università degli Studi di Urbino "Carlo Bo"

Edoardo Scarpanti, Accademia Nazionale Virgiliana

Marco Stoffella, Università degli Studi di Verona

\section{Editorial and Publishing Committee}

Ilari Anderlini

Giannella Biddau

Luigi Diego Di Donna

Edoardo Scarpanti

Open Journal of Humanities $(\mathrm{OJH})$ is a peer-reviewed electronic Scientific Journal, which is devoted to the field of Humanities. OJH will be published three times a year, and will be distributed online with a full Gold Open Access policy, without any embargo period, through a Creative Commons License (CC-by 4.0), according to scientific best practices.

Peer-reviewing process for $\mathrm{OJH}$ is normally operated on a "double blind" basis, for each proposed article, and is conducted by external referees and by members of OJH's Scientific Committee. Both the reviewer and author identities are concealed from the reviewers, and vice versa, throughout the review process. Received articles will be made anonymous by our Editors, before Peer-reviewing process.

Accepted topics of $\mathrm{OJH}$ include the whole field of Humanities, and namely: Anthropology, Archaeology, Arts (Visual Arts, Architecture), Classics, Philology, Philosophy, Law and Politics, Linguistics, Literature, Sociology, Economics. Corrispondent scientific classification in Italy covers the following fields (cf. D.M. 855/2015): Area 10 "Scienze dell'antichità, filologico-letterarie e storico-artistiche"; Area 11 "Scienze storiche, filosofiche, pedagogiche, psicologiche"; Area 12 "Scienze giuridiche"; Area 13 "Scienze economiche e statistiche"; Area 14 "Scienze politiche e sociali". 


\title{
The moral philosophy of nature: Spiritual Amazonian conceptualizations of the environment
}

\author{
Luis Gregorio Abad Espinoza \\ Università degli Studi di Milano-Bicocca
}

\begin{abstract}
It is well known the harmful effects that savage capitalism has been causing to the environment since its introduction in a sphere in which a different logic and approach to nature are the essential conditions for the maintenance of the ecosystem and its complex relations between humans and non-human organisms. The amazon rainforest is a portion of the planet in which for thousands of years its human dwellers have been interacting with nature that it is understood beyond its physical condition. Thus, to what extent Amazonian's approaches to nature could be considered as a moral philosophy through which the way of conceptualizing nature and its non-human denizens enhances the continuity of life and the intimate relations between entities? To answer this question, I will explore the cosmological system of the Shuar of the Ecuadorian Amazon with whom I lived for 5 months between July and November 2018, and thereby elucidate the spiritual relations that this society has with the metaphysical domain of nature.
\end{abstract}

Keywords: Shuar, Ecuador, Amazonia, human-non-human relations, nature-culture dichotomy, cosmology, waterfalls.

\section{Emphasizing nature's agency and its relations with humans among the Shuar}

The Shuar are an Amazonian society who are part of the Jivaro ethnic group that number roughly 85.000 persons 
and are spread between Ecuador and Peru. This group can be divided in two main branches: the Candoa sub-family, including the Shapra and Candoshi, and the Jivaro proper, including the Shuar, Achuar, Aguaruna, Huambisa, and Shiwiar (Taylor 2001). The present article is mainly concerned with a research which I carried out among the Shuar who live in the communities of Tawasap, Yawintz and Wawaim which are located in Morana Santiago province of the Ecuadorian amazon.

The natural environment of the Amazon is a place where relations between entities go far beyond the mere physical realties in which they are immersed. "All things hang together" (Næss 1989: 36), thereby whichever activity undertaken by humans whether harmless as human-non-human relations among the Shuar or harmful as the capitalist market will always confront to a nature with its own intentionality and not an inert object. Indeed, the Shuar could teach us that dwelling in nature is not only an utilitaristic pursuing to attain the necessary conditions for their subsistence, but to dwell within it is to deeply immerse themselves in a sphere where all beings can be connected by the essential elements of this anthropomorphic nature. In this sense, we must emphasize the intentionality of nature's beings who are dwelling and interacting in a natural environment by which since mythical times provide the raison d'être of humans who are physically related to them in the biosphere and metaphysically related in the process of reciprocal sharing of spiritual energy. ${ }^{1}$

1. These relations that I call "reciprocal", contrast with the classic predatory mode of relation that Descola $(1992,1996)$ attributed to the Jivaroan societies. In his analysis, he argued that unlike the Tukanoan so- 
Furthermore, the agency of nature ought to not be reduced as a mere cultural construct in which the rational domain of humans imposed its own abstract categories into the irreducible but misconceived natural environment which remains hidden from the shallow conceptualization of it. It is worth noticing that inasmuch this anthropocentric model to approach to the world continues to permeate our way of thought, will be very hard to plunge into other realities or conceptualizations of a more complex world that not only gives room to the human domain and its cultural traits, but also different intentionalities of the non-human domain of nature or supernature will take part in the reciprocal concatenations that exist in the different worlds of the others. Hence, it could be said that for the Shuar there is no natural domain that exists apart from humans, so, nature is not out there as a passive independent matter with no intrinsic value that only serves as a supplier of the resources for their survival. One day when I was walking in the forest with some children who decided to accompany me from Mura $^{2}$ to the village, we passed across some ants which they quickly recognized as edible, in fact, they started to eat some of them like the chil-

cieties of eastern Colombia (see, Århem 1990, 1996; Reichel-Dolmatoff $1971,1976)$ to whom a reciprocal mode of relation is manifested by a cosmological system in which there is reciprocal chain of interactions between humans and non-humans, namely, a constant exchange and compensation of finite energetic resources is at stake in this cosmology; for the Jivaro, predation is characterized by the total negation of reciprocal feedbacks between humans and non-humans, i.e., when the former consumes the energetic resources of the latter, there is no need of a compensation for this loss of energy.

2. In Shuar "mura" means mountain, and it is a sacred place located in the Twasap community where most of my research took place. 
dren of our cities who eat the candies found in some part of the house. In the same way they recognized the edible leaves of certain plants, the sound of the animals and insects and even described the spirits who still roam in Mura, that is, the ancestors who have transformed in butterflies. ${ }^{3}$ One might say that this approach to nature even for the children is not a trivial one, indeed, in this case the phisicalities of the natural world ought not to be considered as separated from the domain of humans, thereby there are profound interactions between the environment and its non-human dwellers that these are not only known, but perceived and connected with the energy that sustain the life of the universe. Hence, this way of interactions with nature that do not deny the agencies that populate it, are in stark contrast with our conceptions of a somewhat timid different nature. The ontological distinction that exists between our human culture or rational thought and the somewhat mechanical and brute non-human domain of nature, might be considered as an illusory condition of superiority and a some kind of straitjacket in which the radical abstractions of nature and all its denizens warrant the arbitrary, unethical and predatory approach to the matter that must be tame and take advantage of it for the final conquest and victory of the civilization and progress. Some of the features of this abstract conceptualization of the world are well described by Descola who argues that:

3. For the Shuar most of the living and non-living beings are considered persons (aents) and possess a soul (wakan). According to some informants when a human die, his/her soul leaves the body to temporary dwell in different non-human entities like butterflies, animals and trees. I think that this is the reciprocal sharing of energy by the organisms in the ecosystem that I discussed above. 
Typical of western cosmologies since Plato and Aristotle, naturalism creates a specific ontological domain, a place of order and necessity where nothing happens without a reason or a cause, whether originating in God (such as Spinoza's famous 'Deus sive Natura') or immanent to the fabric of the world ('the laws of nature') (1996: 88).

This specific domain which is situated essentially apart from us, and therefore the phenomena that occur or the things which are part of this kingdom, owe their existence and development to a principle extraneous both to chance and to the effects of human will (Rosset 1973). It could be argued that the history of our Western philosophy, in particular since the Ionian natural philosophy, the domain of nature shifted from being the sensible physical nature with all its attributes, diversity and richness that the classic mythical thought conceived as a profound and meaningful anthropomorphic order; to the somewhat universal abstract principle or the basic stuff of all things that the philosophical logos as a new hegemonic way of understanding the world permeated our conceptualizations of it and therefore supplanted the mythical thought and its complexity (Arntzen 1999, 2003). Furthermore, it is worth emphasising the sad truth of the development of naturalism in our civil society, thus, nowadays naturalism, far from being represented by the classic Spinoza's natura naturans and natura naturata, i.e., the former (nature naturing) which is to be understood as the will and power of God to whom all things whether living or not are caused by him; moreover the latter (nature natured) represents all the processes, chains and connections between the objects and the means of comprehending them which are guided by God (1910: 24). It seems that God as an almighty ruler of the world has been dismissed by a more personal and 
irresponsible power that is located no more in a metaphysical omnipresent force, but in a concrete and physical organ that we call brain and whence comes the superior thought that separates us from other entities like animals. In addition, our alleged superiority that places us on the tip of the rational iceberg, segregates the other entities of the natural environment in the cumbersome brute chamber that remains congealed by our scientific knowledge which treats this passive realm as a laboratory to undertake the modern experiments acting like a theistic predatory force. In this respect, following the words of Ingold referring to the so-called rationalistic treatment of nature:

Enlightenment thought has proclaimed the triumph of human reason over a recalcitrant nature. As a child of the Enlightenment, neoclassical economics developed as a science of human decision-making and its aggregate consequences, based on the premise that every individual act in the pursuit of rational self-interest (1996: 25).

Needless to say, according to our western mode of thought, i.e., the radical individualism which more or less permeates the way in which we conceive the "good", or the wellbeing that must be attained at the expense of the others and their environment, is the core of our existence in the world, that is to say, technological evolution has provided us the hedonistic satisfaction to supposedly be the sole masters of the world, or to put it otherwise, the Midasian transformation of the green forests in a river of black noxious oil which is pumped by giant tubes, hence, the green cake becomes a dead polluted desert and the pockets of the few become the tentacles of the octopus that suffocate the world with its black ink of contamination. Moroever, like other territories in the world, 
the Amazonian landscape is increasingly threatened by this unsustainable logic of the market that continues to perpetuate the whims of the mechanical Cartesian dualism. Thus, as Christopher Tilley baldly argues:

The neoliberal-capitalistic Western conception of landscape is that of a surface or volume like any other, open for exploitation and everywhere homogeneous in its potential exchange value for any particular project (1994: 21).

It seems that the selfish economic rationality that pervades in our mechanical naturalist cosmology, strengthens the dualistic conception of our way of being in the universe, that is to say, unlike most of the tribal societies in the world who approach to nature like a home that needs to be in intimate relation with them to provide the necessary conditions for a cyclical process of dwelling in which humans as well as non-humans are part of the entire ecosystem which is enhanced and therefore maintains its equilibrium by these complex relations of entities (see, Rappaport 1979, 2000); Western approaches to nature remain encapsulated in the exclusive bunkers of science and technology that dictate the rules to penetrate the obscure and timid domain of nature, thus, this kind of depredation ought to be understood as an aggressive harassment that remains unpunished for the alleged silent of the timid victim. This supposed silence of nature is well described by Christopher Manes who argues that:

Nature is silent in our culture (and in literate societies generally) in the sense that the status of being a speaking subject is jealously guarded as an exclusively human prerogative (1995: 43).

Moreover, putting a thorny fence to separate the cultural domain and the natural one is a dangerous business that not 
only prevents us to look broader and deeper to different ways to approach to nature, but this radical dualism thoroughly obscures the two-sided interrelationships which exist between people to whom the environment it is to be lived, perceived and above all provides the affordances (Gibson 1979), that influence and shape the way in which these societies adjusts and interacts with their environment.

The importance of the moral values that most of the tribal societies like the Shuar attribute to the whole nature which they conceptualize beyond our rigid categories; must be "taken seriously", as Viveiros de Castro (2011) argues to conceive animism as an ontology whose complexity and seriousness is a matter of extrasensory interactions, indeed, he convincingly puts it:

The anthropologist's idea of seriousness must not be tied to the hermeneutics of allegorical meanings or to the immediative illusion of discursive echolalia. Anthropologists must allow that "visions" are not beliefs, not consensual views, but rather worlds seen objectively: not worldviews, but worlds of vision (and not vision only-these are worlds perceivable by senses other than vision and are objects of extrasensory conception as well) (Ibid.: 133).

As a result, I may argue that the relations that the Shuar have with their natural environment are far from being only visual perceptions of their world, instead their deep immersion in nature is attained by all their senses which are interrelated with the entities of the environment and their senses as well. Furthermore, an ecological anthropology must not neglect the non-passive role that nature plays in shaping the perceptions of the entities who are encompassed by it, in addition, dwelling in the rainforest means to be absorbed in a world where humans and non-humans walk, jump, fly and crawl 
down the storms, the sunlight and the dark of the night which provide the conditions for life in a jungle where to live means interaction and socialization between the human and non-human spheres. Namely, both spheres are not radically separated by the cultural or natural illusory fences as Val Plumwood has argued regarding our Western dualism:

Nature/culture dualism distorts the way we can represent agency in the land, obliging us to view it as either pure nature or as a cultural product, not nature at all, thus hyperseparating nature and culture and representing nature as an absence of the human. Hyperseparation and homogenization lead us to classify the land as pure nature or 'wilderness,' in ways that obscure its continuity with and dependency on culture, and erase the human stories interwoven with it, specially those of its indigenous people. On the other side, conceiving a place according to the opposite homogenized pole of culture has the same distorting result because nonhuman influences and creativities must be erased or reduced (2006: 141).

Conversely, Shuar's conceptualizations of nature place the human domain in an ontological sphere which is not exclusive only to humans, indeed, non-humans are part in a reciprocal metaphysical intercommunication where humanity represents an elementary category through which all entities regardless their external and internal differences are intimately related by a primordial past. Hence, unlike a radical naturalism which puts a fence to hyper separate the cultural and natural domain and thereby it polarizes both spheres as though they were ontologically different; Shuar's metaphysics neither discriminate nor put a boundary among entities who are part of a natural environment whose spiritual energy is shared by them. The moral philosophical conceptions of nature of this cosmology have deep ecological implications 
in challenging Western contemporary ecology which obscures most of the native's conceptualizations of nature giving room only to the rigid categories of science. For instance, about this issue the philosopher Arne Næss clearly writes:

Many of those who emphasize the tremendous breadth of ecology tend, simultaneously, to limit it somewhat. They conceive of it as a natural science or use primarily examples characteristics of natural science. As long as one retains current concepts of nature instead of Spinoza's Natura or other broad, profound concepts of nature, the placement of ecology within the framework of natural sciences favors the shallow ecological movement (1989: 39).

The shallowness of certain ecological movements stem from their own philosophical Western conceptions of nature which scientifically try to seize the natural environment as though it were a mass physically composed by molecules, nutrients and nature's beings whose conservation must be understood as a naturalization of an environment in which the relations with its human denizens are denied. Indeed, native's profound interactions with their environment are thoroughly obscured by the scientific precepts of ecology which give no room to the complex cosmological system of the natives which according to the words of Tzama: "It goes beyond science". ${ }^{4}$ Whereas a debate between two logics of nature is at stake here, I think that it is important to give room to Shuar's moral philosophical approaches to nature which during my fieldwork surprised me the most. Moreover, I will try to describe and analyze some rituals, myths and stories which in my opinion enclose a very profound moral message that teaches us how this society not only interact with nature but mostly respect it.

4. Conversation with Tzama, Mura, Tawasap community, Morona Santiago, Ecuador, 25 August 2018. 


\section{Natemamu and kata the stone of fertilization}

One of the most important rituals undertaken by the Shuar is natemamu, namely, the consumption of natem ${ }^{5}$ by the communities held once a year. It is important to note that only the communities of Tawasap and Wawaim celebrate this ritual on January $5^{\text {th }}$ and $6^{\text {th }}$ the former and in the end of November the latter. It could be possible that the community of Yawintz does not celebrate this because of the nearby location to Tawasap and Mura which is the sacred place where this ritual is held each year, in fact, as Nawech has argued: "I think that the reason why here in Yawintz we do not celebrate the ritual is for the far away distance of the waterfalls". ${ }^{6}$ In this respect, unlike Tawasap which has a sacred place like Mura and Wawaim which has a hill where Nawech's father Sharimiat prepare the ritual and moreover the waterfalls are in the nearby; the nearest "twin" waterfalls are located almost $10 \mathrm{~km}$ away from Yawintz and therefore it is difficult to get there by foot. Unfortunately, I had not the opportunity to participate in the rituals owing to my departure from the field to Italy in the second week of November, however, the procedures of natemamu were described to me in Mura where a sacred circle in whose underground have been buried the ancestors of these people is the place where the ritual is held and in which men and women take part to be baptized by the power of $k a t a^{7}$ or stone of fertilization.

5. A sacred plant also called ayahuasca (Banisteriopsis caapi), through which a decoction is prepared to attain the supernatural realm.

6. Conversation with Nawech, Yawintz community, Morona Santiago, Ecuador, 7 July 2018.

7. The word kata in shuar means penis, moreover, it is interesting to note that according to Tzama this stone has been handed down from genera- 
This peculiar stone which has a form of a big penis is situated in the middle of the circle where is leaned on a piece of trunk near a mortar and pestle to grind tobacco and a pilche or tsapa. ${ }^{8}$ Furthermore, it seems that natemamu in Mura differs to other celebration of this ritual in the different communities, that is to say, because of the presence of kata this ritual acquires an interesting connotation which emphasizes the role of fertility, gender interrelations and the process of life which is sustained by the incorporation of natural elements that afford the interconnection between realms which foster a good biological and spiritual growth and reproduction of the entities involved. The words of Tzama are important to describe the interesting procedures of the ritual:

Here in the circle men and women must sit down on kata to be baptized, then we give men tobacco that they must snuff and we shower the women with ground manioc. Thus, in this way men always will be men and women always will be women.?

It is worth noticing that in this ritual a special role is attributed to certain elements of nature such as the plants of tobacco and manioc and kata which according to the informants this stone encloses too much power. "That stone is extremely powerful" 10 one day Sharian told me when he was visiting Mura to talk with his nephew Tzama. Moreover, tobacco is

tion to generation and thereby he did not know exactly how much time it has been there.

8. Traditional receptacle made of the gourd of the mate tree (Crescentia cujete).

9. Conversation with Tzama, Mura, Tawasap community, Morona Santiago, Ecuador, 30 August 2018.

10. Conversation with Sharian, Mura, Tawasap community, Morona Santiago, Ecuador, 13 October 2018. 
conceived as a plant of male's virility and manioc as a plant of female's fertility whose power must be assimilated by men and women not only for their biological reproduction, but also for the emphasizing of their gender roles that foster the sociocultural continuity and division of labour of this society.

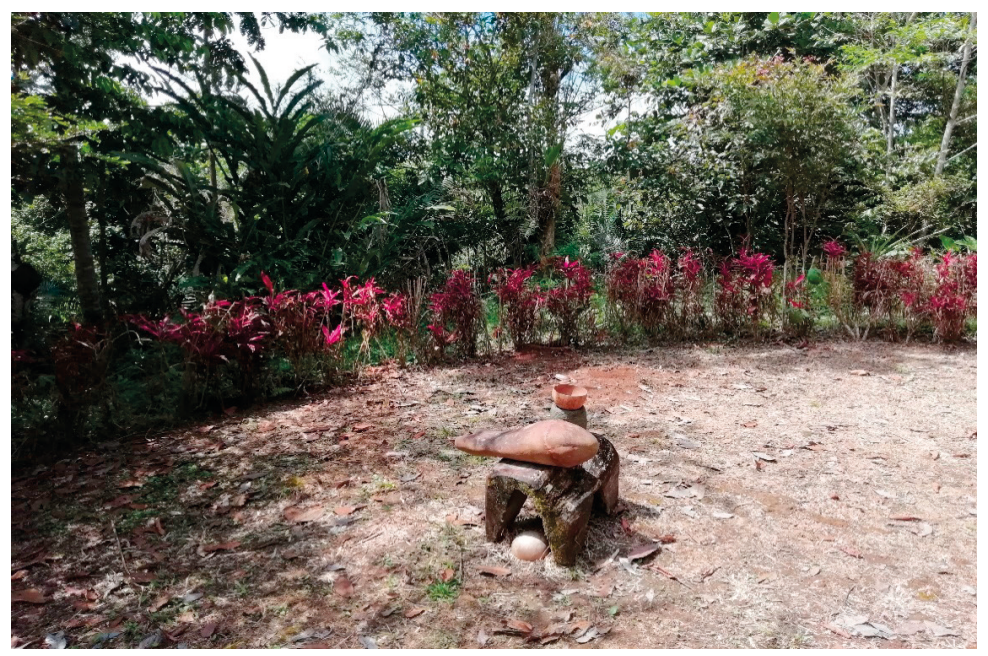

Fig. 1. The ritual circle and "kata" the stone of fertilization.

It might be said that there could be a connection between the reproduction of manioc by the intervention of women who beg $N u n k u{ }^{11}$ for her help in a kind of cooperation between the terrestrial realm and the chthonian realm that provide 11. Nunkui is a mythical being who provides to this society the growth and abundance of the staple crops. Nevertheless, women must respect certain ritual conditions like the chanting of anent or sacred chants in their gardens to beg to this supernatural being for the fertility of the soil and good growth of the tubers. For different accounts of the Jivaroan societies about Nunkui, see, Karsten (2000 [1935]: 112-119); Harner (1972: 70-76); Pelizzaro (1978); Brown (1986: 105-132) and Descola (1994: 192-220). 
the conditions for a fertile soil and a good reproduction and growth of the tubers; and the fertility of women which depends on the assimilation of the fertilizing properties of manioc that has been obtained by women ritual contributions and reciprocal collaborations with Nunkui. Namely there is a cyclical process of reciprocal physical and metaphysical collaborative interactions which in the first case goes from a terrestrial human intervention to a chthonian non-human one, and in the second case from a chthonian non-human intervention to the human terrestrial one.

What about the spiritual power of the big and heavy stone $k a t a$ ? This stone of fertilization ought to be understood as a mere physic inanimate object according to the abstract scientific representations of the world; or as a more profound entity whose power goes beyond the physical and detached perception of it? What anthropologists must do to take seriously a conception of an inanimate object that is beyond our way of understanding and approach to nature which are devoid of any profound conceptions of its agency or spirituality? I think that the problem here is our own perception of nature which is pervasively imbued by scientific radical abstractions of it, thus, to surmount this thorny fence that prevents us a broader and deeper view of the worlds of the others, we must challenge the stark naturalism which arbitrary removes us from the natural environment and its non-human denizens. "The whole is greater that the sum of its parts." (Næss 1995a: 241), this conception of the world is what Arne Næss calls gestalt ontology, namely, the spontaneous experiences of reality and intimate perceptions of concrete things that persons and other conscious beings have with the world; these 
perceptions of the world are considered as more profound than those of abstract scientific representations of it (Ibid). In this sense, the profound spiritual perceptions of nature that the Shuar manifest in a ritual where a somewhat trivial stone is intimately connected with humans, could teach us that the perceptions and relations with this "inanimate" object transcend the brute physical condition of the stone, thereby, the scientific abstractions of nature conceive only certain aspects of it, i.e., the detached physical attributes of nature that obscure the intimate metaphysical relations with it.

Furthermore, as Næss has argued to the impossibility of Western positivists anthropologists to understand the gestalts of the natives to whom a stone is more than a simple hard stone conceived by the former, thus, for the anthropologists would be an illogical absurdity to conceive an inert object as a spirit (1989: 61). In this respect, the philosopher convincingly puts it:

European anthropologists did not often achieve an experience of the shared gestalts of foreign cultures. Natives were 'alogical'. Gestalt thought furnishes the key to communication between dissimilar cultures. Verbal deterioration of gestalts ('a stone is a stone!') implies deterioration of the culture. This is also true of our own culture (Ibid.: 61).

It seems that for the Shuar living and non-living beings are profoundly interconnected beyond their own phisicalities, for instance, a stone that could appear as a simple stone by an outsider, could enclose a powerful essence that cannot be appreciated if one continues to be trapped in a naturalist prison whether it be culturalist or materialist which silences and denies nature's agency and the intimate perceptions of it. In this sense, as kata the stone of fertilization, the waterfalls 
play an important spiritual role among this society, therefore I will describe an interesting ritual where this element of nature is approached respectfully and wisely for a profound connection with the supernatural.

\section{The imploring chants before the sacred waterfalls}

The Jivaro, people of the sacred waterfalls is the name of $\mathrm{Mi}$ chael Harner's book published in 1972, as we can note in the title the waterfalls appear to be a sacred place according to this society. Nevertheless, the book only shallowly explores the complex relations that the Shuar have with the waterfalls for their ritual activities, let alone their profound interactions with these sacred places which unfortunately nowadays are facing the harmful mechanistic logic of nature that Western naturalism has been promoting since its devastating immersion in the heart of the Amazon. Be that as it may, the waterfalls continue to be considered as sacred and important places where the encounter with the supernatural sphere can be attained, however, it seems that in the past the sacred aspects of the waterfalls were more emphasized than today, thus, this aspect is well described by Nawech who remembers an anecdote of his early childhood:

I remember that when I was a child, my grandmother used to tell us that we needed to go to the waterfalls only for ritual purposes. For instance, when the boys went to bath on the waterfalls my grandmother used to say: "It will come a big storm! thanks to those guys who do not respect the waterfalls! ${ }^{12}$

12. Conversation with Nawech, Yawintz community, Morona Santiago, Ecuador, 13 July 2018. 
According to the informant the waterfalls must be approached carefully and with respect, in fact, these are regarded as pure places where one could receive the power of aru$\operatorname{tam}^{13}$ respecting the ritual conditions and practices that this society undertakes in these spiritual places. It is important to note as Tzama perfectly explains that the purity and cleanness of sacred places such as the waterfalls are one of the most important elementary conditions for the arutam visions:

Arutam does not appear in whichever place, he could only appear in clean and sacred places such as waterfalls and mountains, these places are our sacred temples. Only if you are worthy and have consumed sacred plants you can encounter him in these places. ${ }^{14}$

The comparison between sacred places and temples could help us to better understand the importance of these natural places among the Shuar. That is to say, as in a temple one must approach with vehemence to pray and worship a God or any powerful being; to approach to the waterfalls these people chant anent or sacred chants before the waterfalls because these natural places represent the door to encounter

13. According to most of the informants in the communities who continue to follow the ancestral religion, they consider arutam as the most powerful being or energy who can appear in visions, moreover is considered as a God, the father or creator of the Shuar and everything. Nevertheless, only the ones who have undertaken certain ritual procedures and have consumed sacred plants are worthy to receive its power. According to Harner (1962: 260-264, 1972: 135-143) arutam is the "ancient specter" soul that appear in visions, but only in special conditions like the ones described above. In my opinion, it could be possible that being arutam the most powerful entity, was not difficult for the Shuar to more or less equate it to a kind of God, but not the Christian God of course. 14. Conversation with Tzama, Tawasap community, Morona Santiago, Ecuador, 18 October 2018. 
arutam as long as one has respected the ritual procedures to be intimate engaged with the supernatural sphere.

At this point I will describe an interesting ritual activity that I had the opportunity to attend in the ayahuasca waterfall which is situated roughly 1 hour by foot from the Wawaim community. ${ }^{15}$ This was a very exciting but tiring trip that we undertook from Yawintz to Wawaim, moreover, leaving aside the time spent on the pickup to cross the harsh and gravelly paths of the Amazon to reach Nawech's father community. When me and Nawech's family arrived at Wawaim, we needed to go by foot on a muddy and difficult terrain to reach the hill in which Sharimiat was waiting us to bring us to the Ayahuasca waterfall where he intended to undertake the ritual. After we have taking a very good lunch made of fish, meat and manioc, that is to say, the traditional ayampaco ${ }^{16}$ and the classic manioc beer nijamanchi or chicha; we prepared ourselves to walk through the deep jungle to finally arrived on the astounding waterfall where Sharimiat, who had brought a pot of tobacco began to chant the sacred anent before the waterfall and its persisting "sound of rushing water" (Harner 1968), the translation of the chant is described as follows:

I am begging you Grandfather ${ }^{17}$

Crying

Suffering

15. This ritual took place in the ayahuasca waterfall, Wawaim community, Morona Santiago, Ecuador, 1 September 2018.

16. Traditional Shuar dish made of fish, onion, spices and cover with a leaf of a plant called bijao.

17. It is worth noting as has been addressed in the chant, that in Shuar the word apachiru that means grandfather, is interchangeable to the word arutam. 
Imploring

Please come to the waterfalls ${ }^{18}$

(repeat several times)

Although Sharimiat is 90 years old, nonetheless, his voice did not break during the chanting of this anent whose repetition was accompanied by the suffering tone of his voice which seemed a sentimental melodious begging to arutam whose presence is closely connected to the waterfalls. Furthermore, after the conclusion of the chant a row made of boys, Nawech and his family in which I included myself was formed before the waterfall where Sharimiat one by one gave tobacco to be snuffed. After everybody had snuffed tobacco, Nawech wielding a lance began to undertake the ritual greeting anemamu ${ }^{19}$ towards the rushing water of the waterfall to obtain the power of arutam who had been summoned. It is worth noticing that in this case only tobacco was used to undertake the ritual and therefore must be emphasized that the consumption of natem or maikiua ${ }^{20}$ are considered better to encounter arutam in visions, however, this must not be considered a problem for the appreciation of the procedures of the ritual in which the profound relations that this society has with this element of nature is at stake.

18. Anent chanted by Sharimiat in the Ayahuasca waterfall, Wawaim community, Morona Santiago, Ecuador, 1 September 2018.

19. Anemamu is a ritual greeting in which a couple of men talk each other with a loudly voice wielding a lance in a somewhat menacing way. In the past the Shuar used this greeting when a man for the first time met other man and therefore wanted to know who he was or if he was not an enemy. For a detailed description of this ritual greeting, see, Karsten (2000 [1935]: 219-222).

20. A sacred plant (Brugmansia arborea) which is considered the most powerful to reach the desired arutam's vision quests. 


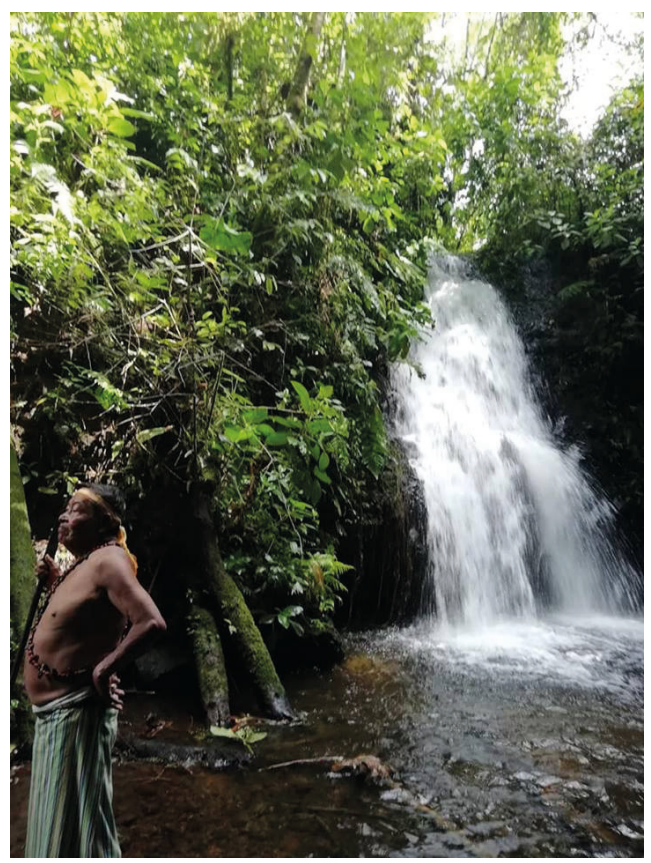

Fig. 2. Sharimiat chanting before the Ayahuasca waterfall.

The subtle procedures of this ritual might show us that a waterfall which for an outsider may be a place for sightseeing or even for a fresh bath in its calm waters or a somewhat violent shower under the rushing water; for this society is a sacred place where its profound and sensible attributes are far from being understood by a shallow naturalist or scientific representations of it, in fact, Shuar's phenomenological perceptions of a waterfall ought to be understood as a complex interrelations of sensible qualities where different feelings decoded by the senses grasp the deep engagement that they have with this natural element. In this sense, as Næss puts it: 
"A joyful experience of nature is partially dependent upon a conscious or unconscious development of a sensitivity for qualities" (1989: 51). In fact, this society experiences its engagement with the waterfalls as manifold profound sentiments that go from feelings of suffering and pain during the chants to feelings of joy and strength when arutam's power has been obtained.

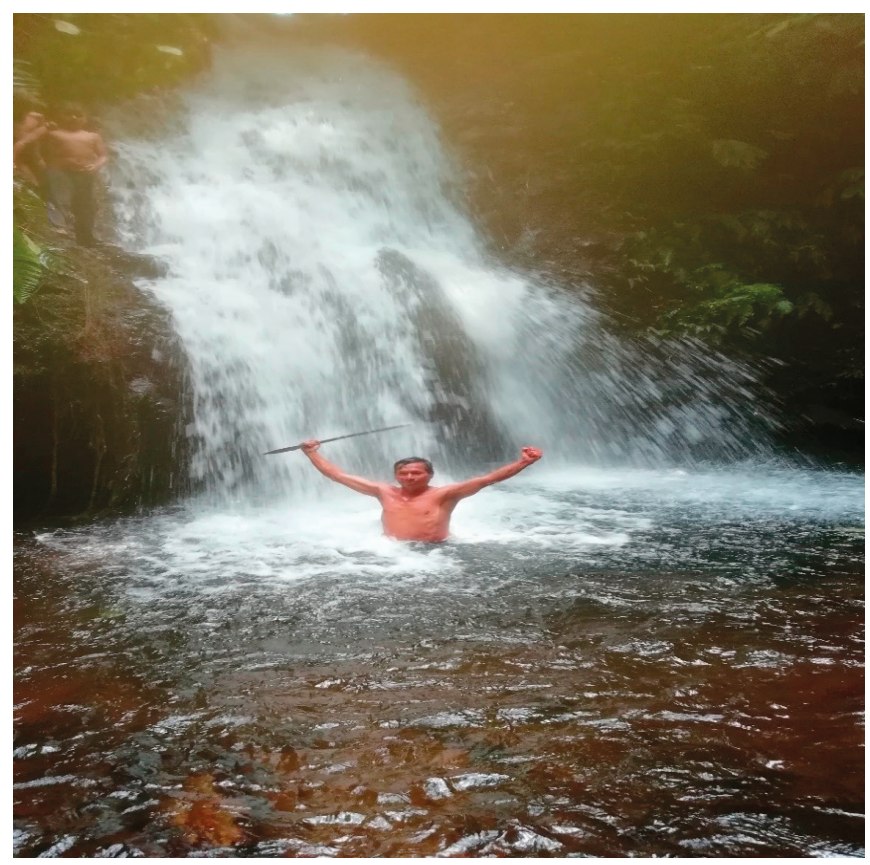

Fig. 3 Nawech during the ritual

One might say that this profound engagement with nature which emphasizes the spiritual dimension of it is in stark contrast with the Western mechanic logic of nature in which the exclusive anthropocentric domain of humans denies any 
non-human's intentionality and therefore coercively silences its metaphysical dimension. This aspect is emphasized by Arntzen who rightly points out:

Human's relationship to the land as spiritual and meaningful in itself is not a historical stage that has been overcome in the Western tradition, but a condition of human's relating to the world that this tradition has largely suppressed (2003: 45).

The suppression of the profound spiritual and moral values regarding the natural environment obliges us to rethink our own concepts of nature which are pervasively permeated by the Western "rational" logic whose rooted values impose to the natures of the others the commoditization and destruction of their own being in their world. In addition, the moral Shuar's approach to nature may not be considered only as a daily life conception, but as the next example will show us, it seems that this is ontologically rooted and conditioned since mythical times.

\section{The noble jaguar in the deep of the Tayos caves}

In my opinion the myth that I will discuss here has a deep moral connotation regarding the relations that this society has with one of the most feared and appreciated but unfortunately in danger of extinction animals. Namely, the jaguar represents the mighty predatory power of the jungle, moreover, his image is one of the most important arutam's visions by which the Shuar acquire this powerful source of spiritual energy. Thus, one day when I asked to Nawech about the famous Tayos caves ${ }^{21}$ in which in the past the Shuar used to go there to hunt the tayos birds (Steatornis caripensis) much

21. Tayos caves are located in Morona Santiago province. 
appreciated for their meat and their bones that were used for making ornaments (see, Karsten 2000 [1935]: 66-67 and Stirling 1938: 110); he began to remind his youth in the military service when during a mission where he had to build paths through the jungle and control the border near Peru; he visited a Shuar's community who according to him used to live in traditional way, i.e., they were barefoot and dressed traditional clothes. Moreover, he asked to them how to get to the Tayos caves and therefore they told him the right direction to arrive there, thus, when he arrived near the caves he saw two very big holes where he and his companions threw some stalks inside and as a result a lot of tayos birds came out like bats. ${ }^{22}$ After Nawech finished to recount his adventures in the military service, he also remembered a myth about these caves that his grandfather and father used to narrate:

In olden times there were tayos birds in abundance, mostly the small ones were more appreciated for their fatty meat. One day a group of persons went to hunt these birds, so, they tied a liana with some stalks which functioned like a ladder to climb down in the deep of the caves. Among the group of persons there was a man who was hated by the others, thus, when all of them were inside the deep of the caves they hunted a lot of tayos and filled all their changuinas (bags) with them. All the group with his filled bags began to climb up the liana leaving the hated man down on the cave, at one point when they arrived up they cut the liana and the poor man remained alone in the deep of the cave. Given that the group had abandoned him alone, this shuar did not know how to do to go out the dark cave, how could he climb such a height which was very rocky? So, this man all the time was crying desperately because he could do nothing inside there. Moreover, it passed a lot of time maybe months or even years since this man had been left inside the cave,

22. Conversation with Nawech, Yawintz community, Morona Santiago, Ecuador, 27 October 2018. 
thus, the tayos used to fly above the man and pooped on his head, then given that the tayos pooped too much his head had peeled! One day the man had fell asleep on the sand of the cave, then a jaguar appeared to him in a dream and said to him: "hi brother! when I will go shouting, you must touch and follow the footprints that I leave! you must follow me because I will go out in a river which is the

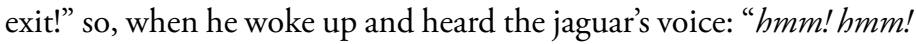
hmm! hmm! hmm! hmm?' then he touched the sand and found the jaguar's footprints, therefore the tired, naked and dirty man began to walk through the dark paths of the cave touching and following the footprints. At one point, after a very long walk the jaguar's voice disappeared! thus, he arrived in a place where it seemed that there was a light which crossed a river "Guangos" in fact, even today people still believe that this is the exit of the cave which ends in the river! Then given that he saw this light he dived in the water and went out in a big pond where he swam a lot to cross to the other side to finally see the jungle, moreover he arrived just in the place where he used to go hunting. Then he arrived at home alive but very tired and with his head peeled due to the very long time in which he stayed inside the cave. At his home his relatives thought that he had died, thus, when they saw him after all of this time they began to cry and organized a big celebration with a lot of dancing and food in honour of his return. This sad myth teaches us how selfish, envious and evil can be the people, look how these persons left alone this man in the cave! they had no compassion of him! from this myth people's envy and selfishness came. ${ }^{23}$

It is important to emphasize that the moral message that this myth conveys regards the selfishness and evilness of certain people who led themselves by hatred without no feelings of compassion to their fellows. Furthermore, the loneliness and desperation of the man to find a way to go out from this dark cave were finally relieved by a dream in which a non-human be-

23. Conversation with Nawech, Yawintz community, Morona Santiago, Ecuador, 27 October 2018. 
ing whose kindness and mercy had helped him to escape from his doomed fate. Indeed, the jaguar whose power represents the most powerful arutam's energy or even the dangerous power of a shaman who can transform in this fierce and predator animal; was the only entity who in this myth saved the dying man to escape from the deep of the Tayos caves. "I believe that mythology, more than anything else, makes it possible to illustrate such objectified thought and to provide empirical proof of its reality" (Lévi-Strauss 1969: 11). In this sense, the proof of the reality of this myth stems from the empirical condition of the jaguar of being an entity whose supernatural power can be understood not as a metaphorical projection of its power that this society undertakes in visions, but as an ontological relation with this entity whose power is spiritually and morally assimilated during the visions or dreams in the case of the myth. Thus, as in the myth the man followed the footprints and voice of the jaguar who led him to the exit of the cave and thereby helped and gave him the force to finally arrive to the jungle and encounter his family; in Shuar's post mythical life, the image and voice of this animal in visions function as the metaphysical conditions for the configuration of the paths that these people will follow during their lives. Then one might say that nature's beings are not only physical entities whose importance depend on humans' classifications of them, to the contrary, non-human beings are deeply immersed in the worlds of humans as the latter are deeply immersed in the worlds of the former. In this sense, according to Næss gestalt ontology as an intimate perception of nature considers "so-called mythic thought is gestalt thought" (1989: 61), in addition, he claims: "If the gestalts rather than their fragments are identified as the 
contents of reality, mythic thought then characterises contents which are largely unavailable in our culture" (Ibid.). That is to say, these contents are the complex spiritual dimensions of the Shuar's mythic thought and cosmology in which profound conceptualizations of nature permit the reciprocal concatenations between humans and non-humans in their natural environment. Moreover, the next peculiar story seems to enclose a deep eco philosophical message regarding the protection of the Amazon rainforest.

\section{Nujank: the guardian of the Amazon rainforest}

One might say that when we talk about Western influence in the Amazon, probably the first thing that comes to our mind is colonialism and its devastating consequences to the natural environment and its denizens. Fortunately, not all the people from the West have embraced the harmful logic of nature by which this is treated as a mean for exploitation to attain the never-ending development of civilization. In this sense, the story that I will narrate here was told to me by Tzama one evening in Mura where the darkness of the hut was only illuminated by a candle and therefore different kind of insects and a dog whose name is Simba were roaming around it accompanying us all the time. According to the informant the events of this story occurred roughly 100 or 150 years ago in the Shuar's territories where a married couple of Europeans arrived in the jungle. The woman was pregnant, thereby she had given birth a child in the middle of the jungle where there was a great storm which made the waters of the rivers rise ${ }^{24}$ :

24. Conversation with Tzama, Mura, Tawasap community, Morona Santiago, Ecuador, 12 August 2018. 
This great current is called "Nujank" and for this reason the tribal leader of the community named the child Nujank. When he was born his umbilical cord was cut and buried in the earth because for each umbilical cord of a child born a new tree would grow according to the ancestral traditions. Then the tribal leader said to the couple that it is better that they return to their home with their child because the dream had come to an end. When Nujank grew up and became a young man, he wanted to know where he was born, thereby he asked to his parents about his story when he was a small child. Then his mother told him the truth and hence he packed up his luggage and went in the deep jungle to discover what had grown from his navel. When he arrived in the community he met a very old man and asked to him: "where I was born? what happened to my navel?" and the old men said to him: "you need to cross that small river and on the other side you will find a very big white tree, this is the tree of your navel!" then Nujank was very happy and crossed to the other side of the river and finally found a very beautiful big tree. He was so excited that he embraced the tree and said to him: "you are my brother!" thus, he looked up and saw that all the trees were embraced by their branches. So, in looking up all these similar trees embraced, he became so excited and began to cry, thereby he said: "now all the trees are the brothers of my brother, for this reason I will call them my brothers" Then he came back to the community and said to the old man: "what can I do to protect these trees?" and the old man said to him: "go to the city and tell to the white men to stop eating and destroying nature, tell to them to stop felling the trees because to fell a tree is like felling the children's navel who are not yet born, is like killing them from the inside, that is, for each tree that they are felling they are killing the lives of the future generations" Thus, Nujank was so astonished that he went to the city to protect the Amazon rainforest and fight against the powerful companies and people that were destroying it. At one point, the police men or militaries attacked him, but while he was still alive he gave to the man that severely wounded him a letter that he had on his pocket. Before he died he said to this man: "please! take this letter to this community" so, the man felt so bad that they had killed a man who was unarmed and only fought for the protection of the forest, thereby he took the 
letter and travelled to the community to give it. In the letter the final words of Nujank said: "thank you for teaching me the value of the trees, I will spend my life in protecting the Amazon rainforest and if I die will be for this reason" This is what our grandfathers used to narrate about the story of Nujank. ${ }^{25}$

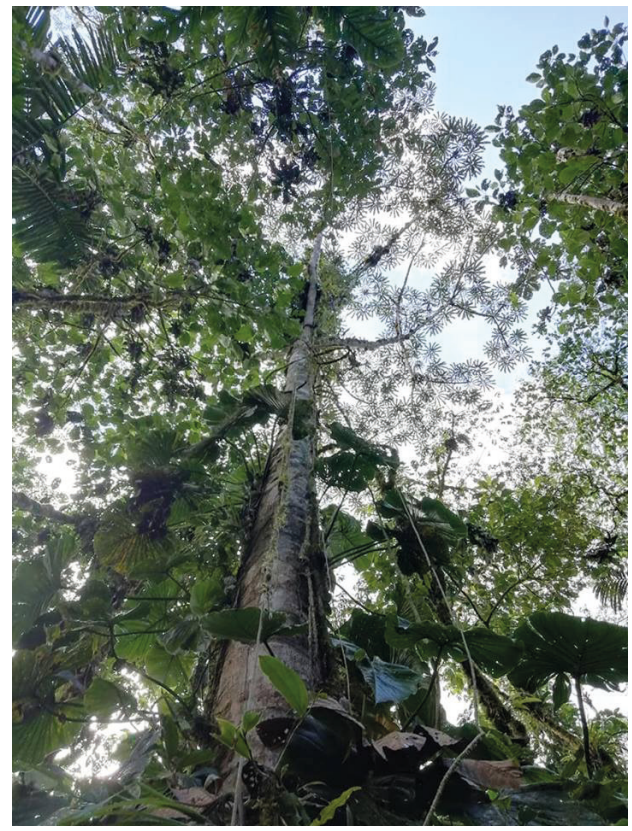

Fig. 4. The trees of the rainforest.

It is important to note how a different, respectful and sustainable logic of nature could be embraced by Western people as in the case of Nujank who understood well the meaningful and profound conception of the forest whose protection and conservation depend whether on the people who dwell with-

25. Conversation with Tzama, Mura, Tawasap community, Morona Santiago, Ecuador, 12 August 2018. 
in it and on the people, who understand its importance for the sustaining of life. Moreover, even if he grew up somewhere in Europe where the predatory naturalist approach to nature was born and moreover took more force during the industrial revolution and colonialism; Nujank was very curious to know where he was born and what happened to his navel which had been buried in the earth as the traditional Shuar's practice. Thus, he prepared himself for a long trip to the place where he was born and where he would find a big tree that after all this time had been growing from the earth in which his navel had been buried. It is worth noticing that the traditional practice of burying the umbilical cord in the earth is still undertaken among the contemporary Shuar though in a less degree than in the past. For instance, according to Tzama: "In the Tawasap community we still cut the umbilical cord of new-borns and buries it in the earth mostly in the ant holes where a new tree will grow" ${ }^{26}$ Furthermore, contrary to the Achuar who bury the placenta instead of the umbilical cord and therefore consider the former as a house in which the soul of the deceased could re-occupy (Descola 1994: 121); the Desana of eastern Colombian Amazon though they bury both ${ }^{27}$ (Reichel-Dolmatoff 1971: 140), nonetheless, it seems that like the Shuar they attribute

26. Conversation with Tzama, Mura, Tawasap community, Morona Santiago, Ecuador, 29 August 2018.

27. It is interesting to note that according to Karsten's observations among the Shuar; both the umbilical cord and the placenta are buried in the earth lest that the dogs or other animals could eat them and thereby could be harmful for the child's life (2000 [1935]: 180). Nevertheless, it seems that he did not find any cosmological attribution to the placenta or umbilical cord. 
special symbolic and metaphysical characteristics to the umbilical cord. In this respect, Reichel-Dolmatoff writes about the connection that the umbilical cord has with Ahpikondia which is for the Desana a kind of paradise:

Primordial placenta was united by an umbilical cord to Ahpikondia, and this idea is expressed even in current belief according to which all human beings are connected during their lives by means of an umbilical cord running invisibly through the rivers and liking the individual to Ahpikondia (1971: 57).

Interestingly even if the Shuar do not endow to the placenta any cosmological or mythological attributes; they nonetheless conceive the umbilical cord as a connection between the earthly life of human beings and the primordial celestial life in which both realms were connected by the liana ${ }^{28}$ and thereby all entities were intercommunicated and interconnected. "With the umbilical cord all of us are connected with the cosmos" 29 one day Tzama told me. Thus, it seems that the association between the umbilical cord and the trees which grow from the earth where the former has been buried; goes beyond any symbolic representation which tries to depict the mythical connection between the earth and the sky. In fact, I think that the connection between these spheres is ontologically related and represented by the elements of nature which try to bridge the gap between the realms whose communication had been interrupted by the misdeeds of primordial times. The interconnection between these elements may be described as follows:

28. In mythical times the earth and the sky were connected by a vine through which all entities could communicate. For a description of the myth see, Karsten (2000 [1935]: 370-371) and Descola (1994: 69).

29. Conversation with Tzama, Mura, Tawasap community, Morona Santiago, Ecuador, 3 September 2018. 


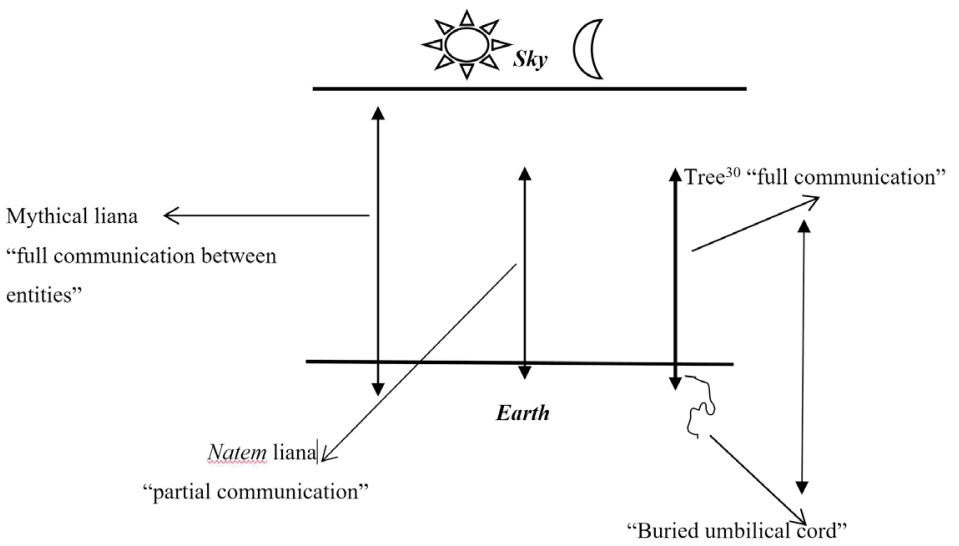

Fig. 5. Interconnection of the elements of nature for the communication between the spheres.

In (fig. 5) we can see how different elements of nature take part in human and non-human relations according to the Shuar's cosmological system which emphasizes the communication between the spheres even in post mythic times. For instance, on the left side of the figure we can see the primordial liana who was the essential condition for the full communication between beings, indeed, when this was cut off the connection between the celestial realm and the earthly one was interrupted. Nevertheless, during post mythic life the Shuar can surmount this interruption by the consumption of natem or the sacred liana located in the middle of the figure, however, this liana can only provide a partial communication between humans and non-human beings, thereby is less effective than the primordial one. The parallel between the Shuar and the Barasana of eastern Colombia is striking regarding the Banisteriopsis caapi vine and its homology with the umbilical cord for the connection with primordial times. 
For instance, according to Christine Hugh-Jones:

Indians do actually say that the river system of the earth is a yagé vine connecting longhouse communities to the ancestral east in the same way as an umbilical cord: they say that when the vine is cut for use, the scar this leaves is a navel (1979: 230).

Moreover, it is worthy to note that the umbilical cord and the tree located on the right side can be understood as the cyclical intercommunication that human beings have with the cosmos during their physical existence; though this communication is constant, this goes beyond the concrete representations of human and non-human communication of the other two elements.

The story of Nujank describes very well the cosmological and moral connotations of the trees which grow from the earth where the umbilical cord had been buried, namely when Nujank looked up to the sky he could appreciate how a big tree had grown from his umbilical cord and which he had named his brother; was embraced with all similar trees, thereby he called all these trees his brothers. Thus, he fulfilled his destiny to protect the forest from the predatory values of its own culture that he had rejected and hence he had embraced the deep spiritual values which had been taught to him by the so-called primitives of the jungle. Moreover, the profound moral message that Nujank's story tries to convey, is that nonetheless he had died by the hands of the people who coercively supressed nature's voice and rights, that is to say, imposing the harmful predatory logic of civilization over the natural environment of the others; his fight to protect the Amazon rainforest might be considered as a rethinking of our own noxious logic to approach to nature and the em- 
brace of a more sustainable, moral and spiritual approach to it which really cares about the future generations and the continuity of all nature's beings lives.

\section{Some reflections from the lungs of the world}

During my fieldwork in the Amazon jungle, many things came to my mind regarding our life in the metropolis and the hyper consumerist and polluting societies in which we are forced to live. When I say that we are forced, I am intending that it is almost impossible to make a radical change in our paths of progress and even survival that we are used to follow in a world where it seems that there is no room to other possible worlds. Be that as it may, even Pope Francis in many of his discourses has strongly restated the failure of the Western mode of development and his struggle to awake the masses and hence to rethink to our own Western values. I think that it is not enough to rethink about our rooted cosmologies, but nonetheless it is the first step to have a deeper and broader view in other possible worlds, that is, the tools of ethnographic research could help a lot to plunge into these different worlds and therefore being immersed in other realities in which our ontological categories are from being universal and useful to understand what is beyond our physical and mechanical world and its realities.

Living among the Shuar, I could realize that our lives in the metropolis are guided by an intolerant clock which does not accept any delay in the mechanic paths of our destiny, that is, our physical life in the universe is subjected by the seeming transcendental rules of the market which give no room to different approaches to the world or ways of conceptualizing 
it that could undermine the illusory democracy which hides the oppressing modern apparatus of the states. It seems that if we try to break the chains which are suffocating the planet and its denizens; a strong sense of loneliness will overwhelm our existence segregating our human condition into a jail in which the other species are forced to stay. This sense of segregation is not only physically perpetuated given that our presence is seen as something weird, fool or even at the limits of madness because we are rejecting the whole cosmological Western precepts which control the entire world, likewise, this segregation is also spiritually perpetuated because our existence is only considered in isolation with the whole world and its entities who share a nature that has been destroyed by the same logic which forces to put ourselves as the only rulers of what seems to be outside us. The dichotomization of body and spirit is not dissolved by a more profound conception of our existence, instead this is disintegrated by an abstract force which is represented in the institutions that we try to promote or even die for them. In fact, what we follow in our lives are the models that have been written to guide our existence to the paths of progress in which only "humans" may unequally partake the pieces or even micro pieces of what has been tamed and exploited for the only sake of the few who decide what is the "good" to be blindly followed.

Perhaps the reader may ask what these words have to do with the conclusion of this article? What do I try to convey in this conclusion? It is worth it a moral commitment to defy our own apparently rooted values? In my humble opinion, what I intended to show throughout these pages is that a thoroughly different world exists in a natural environment 
which is resisting the cannibalistic logic of the moderns, thus, the anthropomorphic nature of the Shuar challenges our seeming scientific logic of what it seems to be nature to us, thereby it seems that a trivial perception of what is beyond its physical features does not do justice to the profound interactions that a society has with non-humans in a complex natural environment which encloses different realities that are ontologically shared by its denizens. Furthermore, the different realities in which the Shuar are immersed ought to be considered as concatenations between ontological levels and non-human entities that provide the meaningful paths of life in the world and cosmos. Hence, for this society the physical realities of life must not be regarded as false or a lie, and thereby only the supernatural sphere must be considered as the real representation of the world (Harner 1972: 134).$^{30}$ In fact, as we could see throughout the pages of this work, for the contemporary Shuar both realties are connected, namely one could not attain the supernatural sphere without follow certain rules and restrictions in the physical sphere, in addition, what one could see in a vision represent a metaphysical reality which its representation derives from the physical world.

In this sense, both realties are interconnected by the ontological juxtaposition and jump of entities which travel between different spheres of reality in a constant external and internal transmutation. I think that this conceptualization of the world could allow us to rethink about the rigid categories which guide our existence in the universe, indeed,

30. It is worth noting that Harner's interpretations of the Shuar's conceptions of the realities was also questioned by Descola (1994: 100). 
this society continues to resist the persisting influence of Western values that destroyed their natural environment and therefore fostered the loss of most of their traditional way of life. Nevertheless, the Shuar struggle for their profound engagement with nature that provides to them a sphere where the physical life of humans and non-humans can be maintained, moreover, is in this sphere that a communication with the supernatural is possible, i.e., in post mythic times a deep relation with nature is the only way to analogically attain the communication of primordial times. In this respect, following the words of Eduardo Khon, the relations that humans have with non-human beings in the different spheres of reality: "Can tell us about how that which lies "beyond" the human also sustains us an makes us the beings we are and those we might become" (2013: 221). In this sense, according to the Shuar what lies beyond the human not only sustain their physical lives in their environment, but non-human entities with their intentionalities help and guide the somewhat unstable human condition to metaphysically build its destiny and hence to physically reproduce what has been revealed during the intimate encounter between the permeable ontological spheres.

From the lungs of the world we can better appreciate what is the meaning of life in a spiritual and profound sense, that is to say, our own existence depends and it is guided by a powerful source of energy that the natural environment encloses, moreover, even if one may argue that nature is separated from us and hence it is an independent domain in which the natural laws reign; how can we explain the 
relations that we have with it even in the plights of climate change and natural disasters which we are facing nowadays? So, it seems that the Western logic of nature which tries to obscure its complexity and makes the other worlds invisible or savage to our eyes, does not take into account the force which is beyond its perception or perhaps tries to ignore it. However, nature gives us the possibility to look for other ways to approach to it, in fact, since the beginning of humankind we could choose the paths to be related with it and therefore adapt ourselves not in a passive medium in which we imprinted our superiority among the other entities; but in a sphere where humans are only a part of a more complex concatenations of beings who share a natural environment which is beyond its physicality. In this sense, Shuar's moral philosophy of nature could teach us that an "anthropology beyond the human" (Kohn 2013) is not only possible to think, but it is highly necessary to promote for a better valorisation of more sustainable ecological approaches to nature which ensure the full richness and diversity of life-forms on the earth (Næss 1995c: 464) both humans and non-humans.

At this point, one might question my argument by which these complex and profound interactions with the natural environment could be considered as a moral philosophy and a more sustainable and spiritual way to approach to nature. In addition, one might think that I am trying to idealize or even essentialize Shuar's conceptualizations of their relations with non-humans, hence, as much as utopic my argument might seem I think that our Western ethnocentrism does not permit to take serious other possible 
relations with the non-human kingdom that could prevent the collapse of the entire ecosystem in which our rationalities are not capable to grasp the different dimensions of what we call simply nature. Moreover, there is a big difference between a logic of nature that has been coercively imposed and a logic that has been passively adopted without resistance. For instance, in one article Descola (2005: 33) has argued that in the mid-seventies he had the opportunity to give several lectures to the leaders of the Shuar Federation (FICSH) to warn them of the harmful consequences to the environment that the massive program of cattle-ranching launched by the Federation years before could cause. Moreover, it seems that the Shuar proceeded with the program until they finally realized that the forest began to disappear, and the soil were irreversible damaged. Thus, the French anthropologists concluded that the Shuar did not avail to their profound knowledge of the environment which has been build up generation after generation given that this knowledge was mainly practical, non-reflexive, non-objectifiable, and thus non-applicable to new contexts where it might have proven useful (Ibid.). Furthermore, even if Descola's conclusion could seem plausible in a context in which the Western market values have been apparently assimilated by the Shuar; I think that the assimilation of these values passed through a process of imposition in which a predatory logic of nature had been masked by the deceiving modern progress which could have seemed attractive to the Shuar who wanted to join the institutions of the State and thus increase their possibility of being heard by the latter to foster their rights. 
Indeed, I think that it is not that they knowledge is only practical and non-reflexive, but this is reflexive inasmuch their conception of being in the environment does not encounter other conceptions which are part of other systems of rationalities that conceive the natural environment as a segregated commodity. For instance, is not the same to throw away in the jungle a bag made of fibres and a bag made of plastic, that is, the first one is produced by the Shuar that know very well its materials which are obtained from nature with no industrial intervention; but the things are way different with the plastic bag which is made by heavy technological interventions in nature that extract a natural resource that had been underground for millennia, hence, when the Shuar for the first time saw a plastic bag they did not realize what was behind the apparent innocuous plastic which has been one of the many causes for the destruction of the Amazon rainforest.

One may say that if it were for the Shuar and for other Amazonian societies, the oil would still be underground, and a great part of the rainforest would be much less destroyed and probably the planet would be much less polluted. In fact, one cannot deny in this case how harmful can be a radical different approach to nature when is imposed into the worlds of the others in which the relation with nature is not an economic one but a cosmic one. Indeed, as Næss has argued that most of the approaches to nature in the world could be compatible with nature, namely, only the Western approaches promoted by industrialized countries are against it (1995b: 398), thus, the only thing that remain to ask is which logic is wrong according to nature? 


\section{References}

Århem, K. 1990. "Ecosofía makuna." In Correa, F. ed. La selva humanizada: ecología alternativa en el trópico húmedo colombiano. Bogotá: Instituto Colombiano de Antropología. 106-126.

Århem, K. 1996. "The Cosmic Food Web: Human-nature relatedness in the Northwest Amazon." In Descola, P. and Gísli, P. eds. Nature and society: Anthropological perspectives. London/New York: Routledge. 185-204.

Arntzen, S. 1999. "Is Presocratic Philosophy of Nature a Source of ManNature Dualism?" In Boudouris, K. and Kalimtzis, K. eds. Philosophy and Ecology. Vol. II. Athens: Ionia Publications. 22-31.

Arntzen, S. 2003. Cultural Landscape and Approaches to Nature Ecophilosophical Perspectives. Norway: Telemark University Collage.

Brown, M. 1986. Tsewa's gift: magic and meaning in an Amazonian society. Washington: Smithsonian Institution Press.

Descola, P. 1992. "Societies of nature and the nature of society." In Kuper, A. ed. Conceptualizing societies. London: Routledge. 107-126.

Descola, P. 1994. In the Society of Nature: A native ecology in Amazonia. Cambridge: Cambridge University Press.

Descola, P. 1996. "Constructing natures: Symbolic ecology and social practice." In Descola, P. and Gísli, P. eds. Nature and society: Anthropological perspectives. London/New York: Routledge. 82-102.

Descola, P. 2005. "Ecology and Cosmological Analysis." In Surrales, A. and Hierro, G.P. eds. The Land Within: Indigenous Territory and the Perception of Environment. Denmark: IWGIA. 22-35.

Gibson, J. 1979. The Ecological Approach to Visual Perception. Boston: Houghton Mifflin.

Harner, M. 1968. "The Sound of Rushing Water." Natural History 77/6: 28-33; 60-61.

Harner, M. 1972. The Jivaro, people of the sacred waterfalls. Garden City: Doubleday, Natural History Press. 
Hugh-Jones, C. 1979. From the Milk River: Spatial and Temporal Processes in Northwest Amazonia. New York: Cambridge University Press.

Ingold, T. 1996. "The optimal forager and economic man.” In Descola, P. and Gísli, P. eds. Nature and society: Anthropological perspectives. London/ New York: Routledge. 25-44.

Karsten, R. 2000 [1935]. La vida y la cultura de los Shuar. Quito: Abya-Yala.

Kohn, E. 2013. How Forests Think: Toward an Anthropology Beyond the Human. Berkeley: University of California Press.

Lévi-Strauss, C. 1969 The Raw and the Cooked. New York: Harper \& Row.

Manes, C. 1995. "Nature and Silence." In Oehlschlager, M. ed. Postmodern Environmental Ethics. Albany: State University of New York Press.

Næss, A. 1989. Ecology, Community and Lifestyle. Cambridge/New York: Cambridge University Press.

Næss, A. 1995a. "Ecosophy and Gestalt Ontology." In Sessions, G. ed. Deep Ecology for the Twenty-First Century. Boston/London: Shambhala. 240-245.

Næss, A. 1995b. “The Third World, Wilderness, and Deep Ecology." In Sessions, G. ed. Deep Ecology for the Twenty-First Century. Boston/ London: Shambhala. 397-408.

Næss, A. 1995c. "Deep Ecology for the Twenty-Second Century." In Sessions, G. ed. Deep Ecology for the Twenty-First Century. Boston/ London: Shambhala. 463-468.

Pelizzaro, S. 1978. Nunkui. Sucua (Ecuador): Centro de documentación e investigación cultural shuar, Mundo shuar, Series F, No 8.

Plumwood, V. 2006. "The concept of a cultural landscape." Ethics and the Environment 11/2: 115-150.

Rappaport, R. 1979. Ecology, Meaning and Religion. Berkeley: North Atlantic Books.

Rappaport, R. 2000 [1968]. Pigfor the Ancestors: Ritual in the Ecology of a New Guinea People. Long Grove, Illinois: Waveland Press, Inc. 
Reichel-Dolmatoff, G. 1971. Amazonian Cosmos: The Sexual and Religious Symbolism of the Tukano Indians. Chicago: University of Chicago Press.

Reichel-Dolmatoff, G. 1976. "Cosmology as ecological analysis: a view from the rain forest." Man 2/3: 307-318.

Rosset, C. 1973. L'anti-nature: Eléments pour une Philosophie Tragique. Paris: Presses Universitaires de France.

Spinoza, B. 1910. Ethics. London: J.M. Dent \& Sons Ltd.

Stirling, M. 1938. Historical and ethnographical material on the Jivaro Indians. Smithsonian Institution Bureau of American Ethnology, Bulletin 117. Washington.

Taylor, A.-C. 2001. "Wives, Pets, and Affines: Marriage among the Jivaro." In Rival, L. and Whitehead, N. eds. Beyond the Visible and the Material: The Amerindianization of Society in the Work of Peter Rivière. Oxford: Oxford University Press. 45-56.

Tilley, C. 1994. A Phenomenology of Landscape. Places, Paths and Monuments. Oxford: Berg Publishers.

Viveiros de Castro, E. 2011. "Zeno and the Art of Anthropology: Of Lies, Beliefs, Paradoxes, and Other Truths." Common Knowledge 17/1: 128-145. 